\title{
DESIGN AND DEVELOPMENT OF A TECHNOLOGICAL SYSTEM FOR GREY WATER REUSE
}

\author{
BEATRIZ GARZÓN \& LEONARDO PATERLINI \\ Architecture and Urbanism Faculty, National University of Tucumán, Argentina
}

\begin{abstract}
The purpose of this work is to contribute to the decrease in the consumption of drinking water. As well as sustainability, its objectives are to design, develop and transfer a non-conventional system for this purpose and to improve the hygiene and habitability conditions of sanitary spaces. In order to achieve this, the paper proposes the involvement of the community in order to ensure that the described social changes take place, replacing the traditional toilet system by a newly designed flush unit. With regard to the results achieved, the work has two stages, comprising: 1. The development of the theoretical framework; a study of the history and an analysis of the geography of the areas of application; the generation of possible solutions in response to the system; the selection of the best proposal; and 2. The adjustment of this proposal; the preparation of technical documentation; the design for the building process; the adjustment of its operation, use and maintenance; its materialization; experimentation and evaluation. It was concluded that this system is adaptable and affordable, offering easy construction and installation work - features that make it an eco-friendly as well as sustainable product. This makes it possible to take care of the environment.

Keywords: rational use of the water, approachable technologies, habitat sustainability.
\end{abstract}

\section{INTRODUCTION}

This work seeks to promote 'clean' technologies, within a social framework, in order to help understand the need for change, which must be addressed to improve the population's quality of life and maintain our ecosystem for future generations.

\section{GENERAL OBJECTIVES}

The general objectives of this work are as follows:

- To generate a product whose investment justifies its implementation in social buildings, at an application cost in accordance with the economic capacity and the social situation of its users-builders.

- To apply this system in the sanitary spaces of buildings with social interest.

- To demonstrate and disseminate its proper function and to implement the system.

The work's specific objectives are as follows:

\section{SPECIFIC OBJECTIVES}

- Environmental objectives:

- To promote and generate alternative and sustainable technology through the suggested system, strengthening and emphasizing their acceptance and an understanding of the fact that they add value to the product.

- To disseminate and demonstrate the suitability of grey water reuse.

- Productive objectives:

- To generate a national product, able to compete in the local market against industrialized alternatives of foreign origin. 
- To build a low-cost system using local resources. To achieve a simple product, capable of being developed with simple manufacturing processes.

- $\quad$ To achieve a product capable of being used in social architecture.

- Social objectives:

- To appeal to the low-income population, with useful tools to improve their hygiene conditions, well-being and comfort, causing the minimum possible disturbance to their natural and cultural contexts.

- To adopt and implement prototypes and technology for the recycling and reuse of grey water, taking into account the sites' requirements and conditions environmental, technological, cultural, productive, health, etc.

- To encourage cooperative work, according to the size of communities and families.

- To promote integration and social inclusion.

- To implement and comply with the tenets of green and decent work.

\section{ISSUES AND ADVANTAGES RAISED}

The study raises the following issues:

- Rational use of water. Water shortage is a problem worldwide, as well as in this country in general and in the province in particular, with the industrial and agricultural sectors being places where there is greater consumption. This case will use home consumption values as a reference. "Wastewater reuse in agriculture is a way of recycling water and purifying nutrients. This reuse also allows the environmental impact to be reduced..." [1]; see Fig. 1.

- Grey water reuse. Grey water consists of all wasted water generated in households from streams without fecal contamination: for example, the water that comes from bathtubs, sinks, dishwashers or washing machines. At first glance, this water seems to have no value, but we understand that, by means of a simple treatment, it can be reused, thus extending its life cycle and adding value to its use. Moreover, the growth in population and the indiscriminate use of drinking water makes it necessary to 'reuse' as much as possible. This reuse enables a decrease in the use of drinking water, creating a product that will allow the reuse of grey water produced by the bathroom sink: storing it in the toilet cistern so that it can be utilized to flush the toilet.

- The use of this device will allow the saving of approximately 15 liters per day per capita, generating, for example, in a household of four people, an estimated saving of 1800 liters a month. This decrease in consumption will be of great importance in areas where the distribution of water is unequal, failing to meet minimum requirement levels.

- Advantages of grey water use. Among other aspects, the benefits of grey water reuse are: a decrease in the use of drinking water and of the urban network and treatment plants; highly effective purification; a solution for places where other types of water treatment cannot be used, decreasing the amount of energy used for treatment and pumping to places where there are no other kinds of water; the recovery of nutrients that are otherwise lost.

One disadvantage of water reuse systems is that they have specific requirements that make their use difficult in certain situations. Space and installation dimensions 


\begin{tabular}{|lc|}
\hline \multicolumn{2}{|c|}{ Average daily water use per person } \\
\hline Shower & 80 Its. \\
\hline Sink & 18 Its. \\
\hline Toilette & 60 Its. \\
\hline Bidet & 2 Its. \\
\hline Clothes washing & 15 Its. \\
\hline Dish Washing & 20 Its. \\
\hline House Cleaning & 15 Its. \\
\hline Irrigation & 30 Its. \\
\hline Daily average & 240 Its. \\
\hline
\end{tabular}

Figure 1: Water use per person.

must allow the water treatment process to be developed. "One of the most common disposal practices of domestic wastewater has been direct disposal without treatment. This can generate some health problems in the population: for example, infectious diseases, whose pathogens are efficiently dispersed into the environment..." [2].

Normally, grey water does not acquire the characteristic of being extremely dangerous for health or the environment (the concept of black water is understood as effluent that has fecal contamination), as it must submit to effective treatment before flushing or reuse, avoiding some undesirable effects or diseases.

\section{ALTERNATIVES FOR THE REUSE OF GREY WATER TECHNOLOGY IN TOILETS}

"There are grey water collection systems that send used water directly to the points of use without pretreatment. These systems do not carry out any treatment on the grey water" [3]. There are products on the market that allow grey water reuse. These work without any problem but, in some cases, require alternative energy for their operation, pumping elements which are expensive, purifying chemicals, or the loss of space for the placement of the product, among other drawbacks.

The developed proposal aims to change the way we think, create, produce and use these devices, optimizing the use of water, generating minimal spaces and providing a satisfactory solution to the user.

\subsection{Design, development and experimentation of alternative systems for grey water reuse}

We propose the development, experimentation and implementation of strategies and actions to achieve a grey water recycling system from the bathroom sink. Due to the growth in population, it is necessary to take care of this essential life element, water. The indiscriminate use of water makes it necessary to 'recycle' as far as possible. The case we propose is the employment of grey water for toilet flushing.

It is important to consider which will be the most suitable treatment system. It should be designed for specific conditions, and natural and cultural conditions must be involved. 
When treatment systems are installed, it is important to consider not only the effectiveness of purification but also the relationship with the surrounding elements, special requirements, economic cost, maintenance and disposal, among other aspects.

The materials selected for the construction of the device should facilitate manufacturing and must be capable of resisting long-term exposure to humidity. In addition, a waterproof vessel capable of containing the reused water should be provided. It should also be low cost and have humidity-resistance properties.

With regard to the above, three proposals are put forward:

\subsubsection{Fiberglass prototype}

Fiberglass has good malleability and ductility characteristics for generating parts of different shapes, dimensions and custom designs.

Fiberglass construction methods make for easy serial production of the designed product. An array of the elements is constructed, from which successive copies are made: as many as are required.

Other advantages are as follows: this material allows custom design (gives design freedom, thus user's choice) and a finish; the weight of the device is considerably reduced, when compared with ceramic cisterns. This device covers all necessary technical characteristics for the right operation. Training of the labor force is very simple, with tools available on the market at lower costs.

\subsubsection{Prototype 2 stainless steel}

Like the previous alternative, stainless steel provides suitable features, in terms of its resistance to corrosion, oxidation and impacts; hygiene-cleaning properties; esthetics; excellent weldability; and ease of molding in relation to other metallic materials. All these

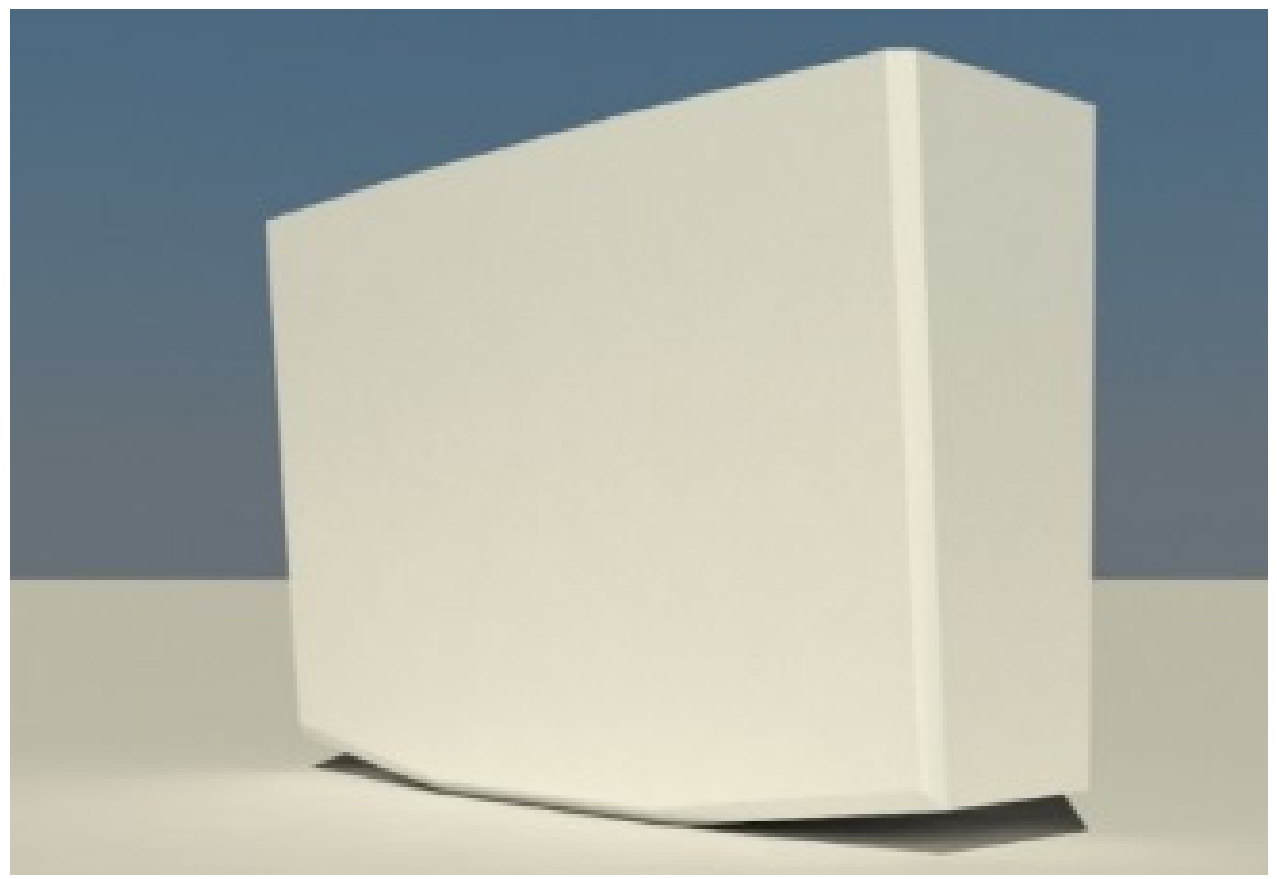

Figure 2: Design of fiberglass cistern. (Source: authors’own.) 


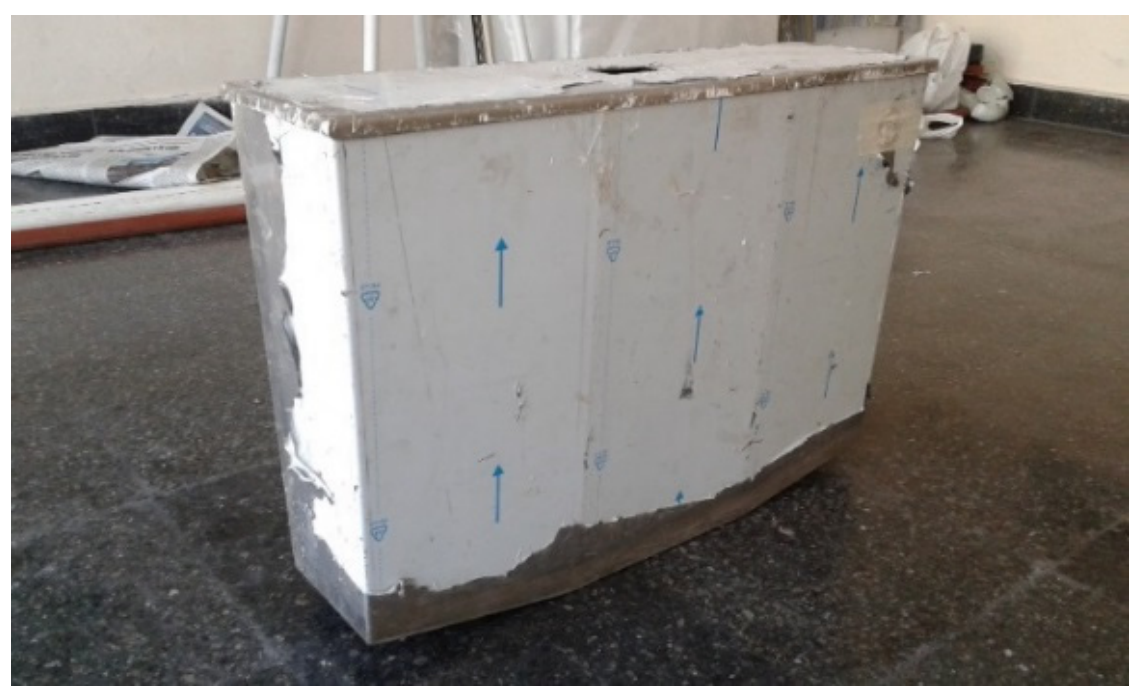

Figure 3: Stainless steel backpack. (Source: authors'own.)

properties mean that stainless steel leaves no doubt about its problem-solving capacity. Environmental and health issues have increased the use of stainless steel. It must be mentioned that a prototype in this material, with the dimensional, geometric and morphological characteristics has been built.

5.2 Design, development and experimentation of alternative technologies for accumulating and filtering grey water

The device under discussion is one that receives grey water from the bathroom sink. Then, through a chemical process, it eliminates bacteria and other items that could produce smells or pollution, affecting environmental health. Then, the cistern can flush the contained water, completing the process.

The task has been to develop a device integrated into the already existing system, avoiding the need to add more objects, because bathroom spaces are small in size. Also, this keeps in mind the user's opinion, which often does not like the idea of putting new technological objects into sanitary cores.

In the search for an alternative system with such features, the superior proposal was an object which in itself contains all the functions and parts necessary for its operation and a container of reduced dimensions. This allows, in bathrooms, a change from the conventional cistern to the proposed device with few modifications.

It is a product with low visual impact for users because all the grey water system parts are contained inside.

\subsection{Integration of the bathroom system}

This is an easily installed and simple construction system, with the ability to be adapted to any conventional bathroom, being affordable for those which already exist; see Fig. 4. Another important issue was to achieve clarification and purification of the water. To solve this, bleach tablets must be inserted into a reservoir inside the cistern toilet. No other treatment is required. 


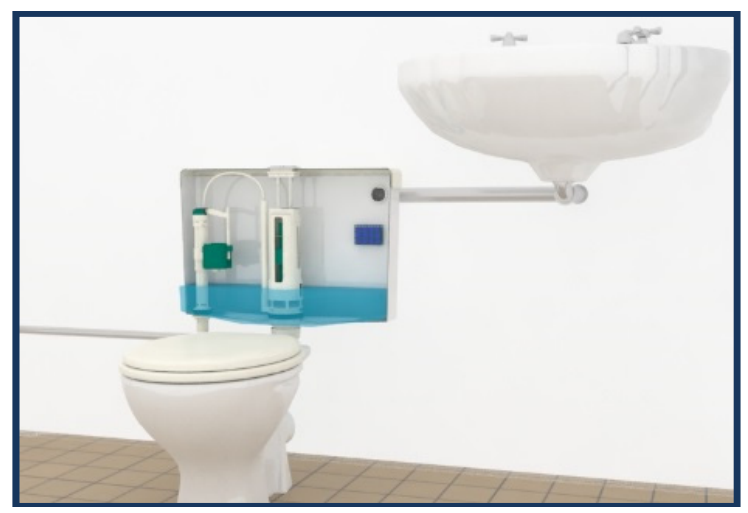

Figure 4: System integration 3D image. (Source: authors' own.)

\section{OPERATIONAL AND FUNCTIONAL DETAILS OF THE PRODUCT AND ITS EXPERIMENTATION}

For the correct implementation, design and experimentation of the system, we worked with a PVC cistern, acquired commercially. Different tests were performed on it. This helped in obtaining an adjusted design as well as the technical parts of the system. Conventional backpacks are equipped with: a $1 \frac{1}{2}$ " water inlet at the bottom; a download that is resolved with a set of bellows, curved and connected to the toilet, which is the means by which the downloaded water will run; a pump system of double volume, which allows a download of 9 or 12 liters of water, as appropriate; a top access cover to connect for maintenance of the backpack - it has a button, which, according to the manufacturer, is cylindrical or prismatic. Our own grey water recovery system accessories comprise a rear entry of $40 \mathrm{~mm}$ with a flange connection to avoid leaks. The tube comes directly from the basin and deposits the water in a PVC spout of $40 \mathrm{~mm}$ with perforations. The pipe is wrapped in a filter of fats that is can get in any trade of the area. Before entering the backpack, the water goes through the said filter, leaving all the sediment (SOAP, toothpaste, etc.) behind. According to the manufacturer, the filter should be renewed every three months. This task would be performed by lifting the top of the backpack, removing the PVC pipe and replacing the filter. It should be clarified that the PVC pipe is attached by pressure to the pipe coming from the basin; see Figs 5 and 6.

The backpack has on the front an access for water purification tablets. It consists of a flange of polypropylene with $90^{\circ}$ elbow connected to a perforated pipe of the same material reaching the minimum water level. When the water level comes up, the bleach pads inside the pipe become in contact with water, which in this way is purified. The pads must be replaced approximately every two months.

\section{CONSTRUCTION OF THE PROTOTYPE}

\subsection{Glass fiber backpack}

The fiberglass backpack is built using a stainless-steel mold. It consists of several layers of glass fibers and adhesive. Two pieces of steel are incorporated when building the layers which add rigidity to the backpack and allows it to be hung it from the wall After that, the necessary holes are drilled and pipes fixed as shown in Fig. 6. 


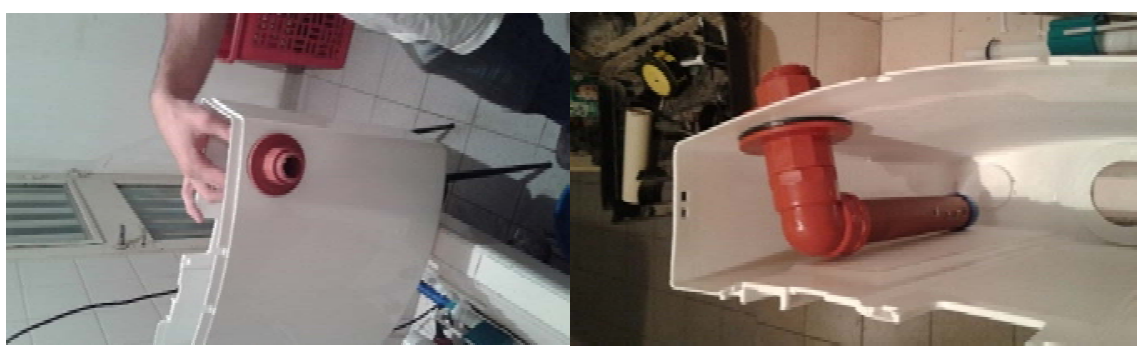

Figure 5: Operational and functional experimentation.

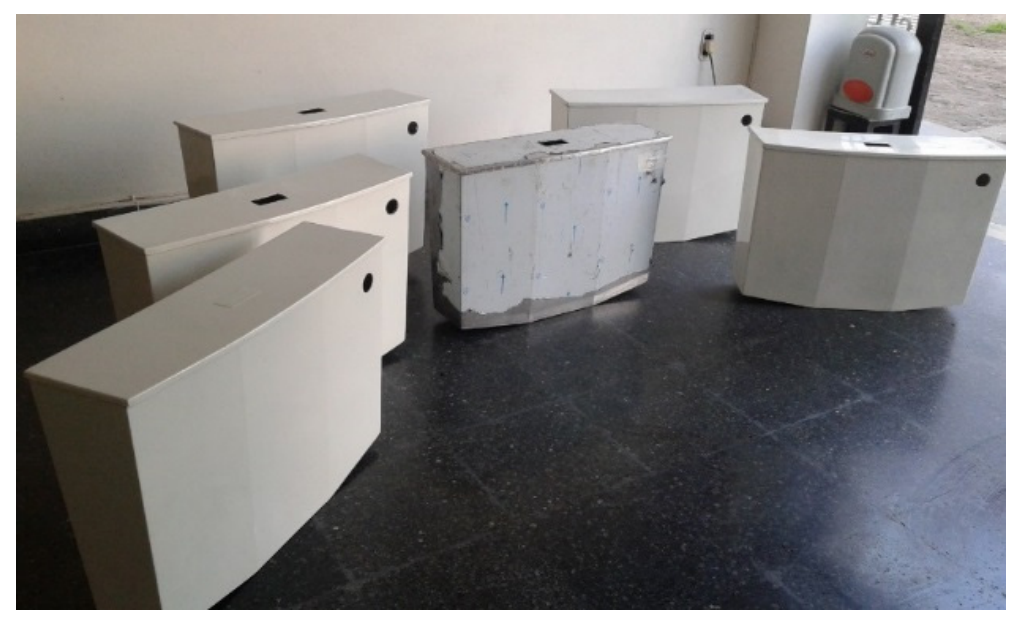

Figure 6: Packaging design. (Source: authors’ own.)

\subsection{Backpack in stainless steel}

The most suitable material for the backpack was 'a priori' determined to be fiberglass. In meetings with other specialists however, it emerged that there is a need for them to be also in stainless steel. In this case one starts with a stainless-steel sheet which is cut and the different parts welded with great precision The necessary are cut afterward, before polishing the surface as a final step

Once the prototype in stainless steel was completed, some of its disadvantages became noticeable: excessive weight (even without being filled with water) and the high price per unit of the finished backpack that emerged from an analysis of costs.

\section{DESIGN AND IMPLEMENTATION OF THE GASKET, CAP AND LOGO}

\subsection{The packaging}

The materialization of the packaging led to a major investigation, which opened some doors to future interventions and work with the material, paper carton, a product that was widely accepted for recycling at the time. 


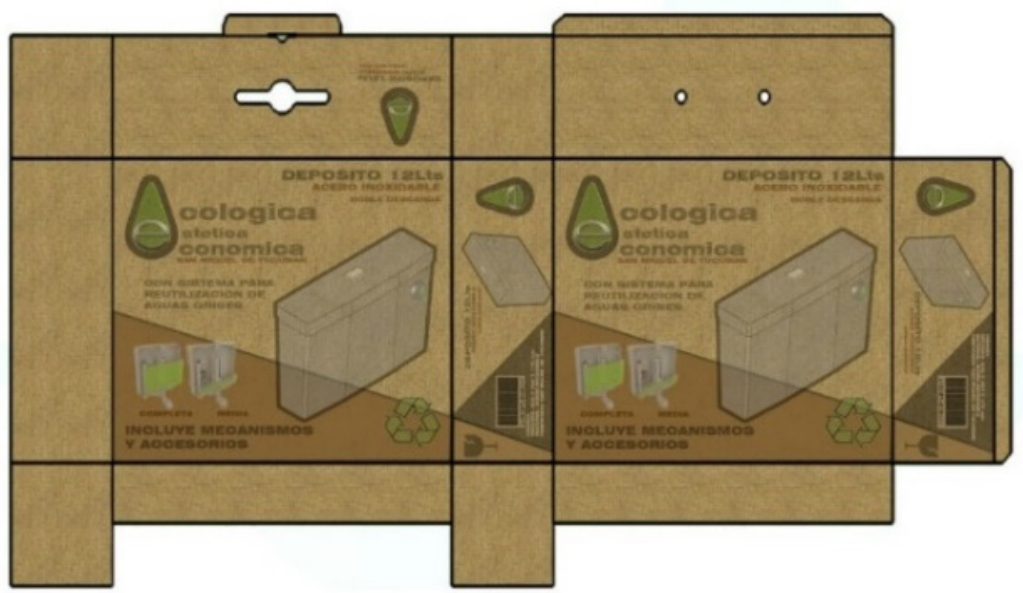

Figure 7: Packaging design. (Source: authors’ own.)

It was necessary to identify centers for the collection and recycling of the same, but in which the cardboard is sent to other cities for recycling. In Tucumán there aren't many places that work with recycled cardboard.

The packaging was worked up by a factory that made cardboard boxes from recycled paper.

The decision to construct the box in a briefcase shape, was tested with all the products inside and, after an evaluation, it was observed that the box was very practical for transportation. With an appealing and easily identified design, samples produced in the Faculty of Architecture and Urbanism at the National University of Tucumán were well received.

\subsection{The access cover and logo}

Regarding the problem of the name/logo, at the same time, the issue of gaining access from the front of the backpack was raised. Both problems were dealt with together, giving a unique solution. The access cover and the logo would be one and the same object, concealing a flange behind it.

\section{EXPERIMENTATION AND EVALUATION OF THE FULL SYSTEM}

A real-scale prototype was made. In the workshop, the construction of a demonstration model proceeded, including a sink, a toilet and the system for collecting grey water. The prototype was assembled on a metal structure, with the floor and wall simulated with bolted plates of superboard. On the plates, sanitary items with all their fixings were arranged in the same way as if they were placed in a health center. The idea of this prototype with all the elements in operation is to evaluate the system in a controlled environment in order to make any adjustments that are necessary for the following stages. After washing hands in the sink, the water goes, by gravity, within the pipes behind the wall plate to get to the point of access of the water behind the backpack. At this point, a problem was seen with the first filter that had been decided on: the wáter tended to stall, as the said filter did not have the required speed to allow the entry of the water. The scale model allowed us to then evaluate the chosen filter to improve this issue. 


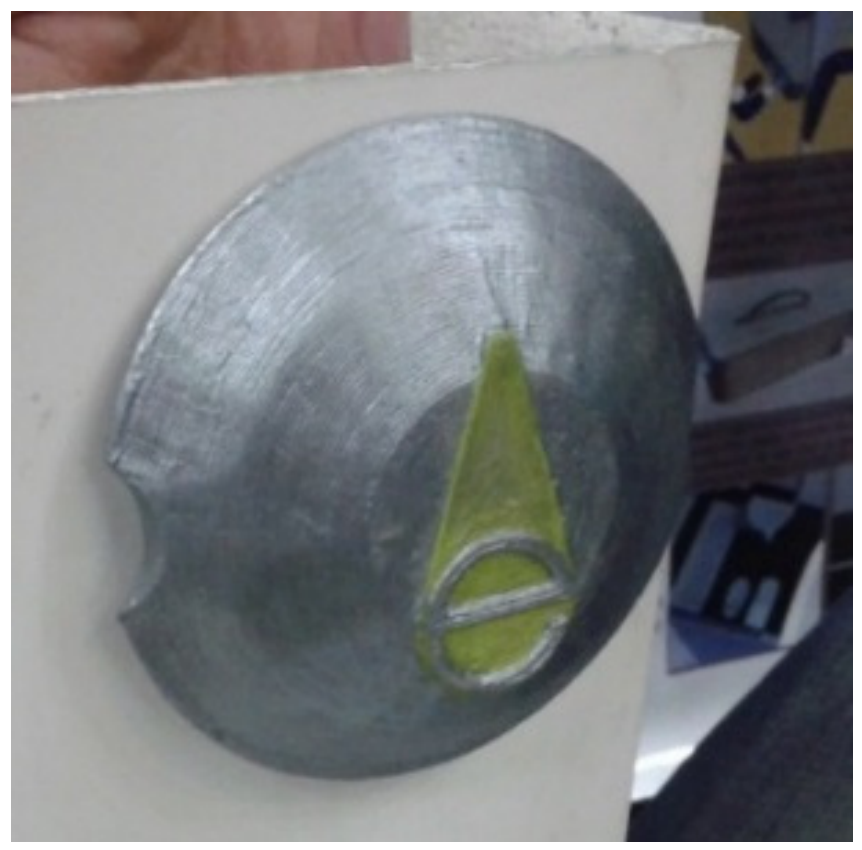

Figure 8: Cover. (Source: authors' own.)

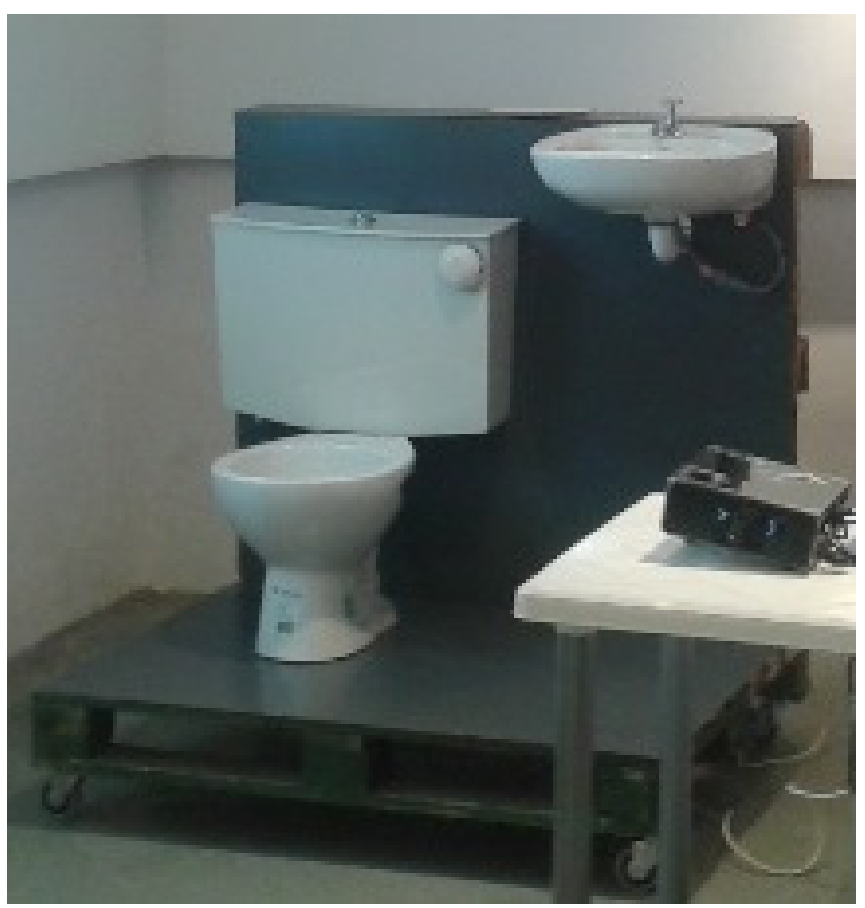

Figure 9: Real-size model exhibited at the Tucumán Expo Fair, 2015. 
Starting from the entrance to the backpack, the water is exposed to the water treatment tablet that removes the color and also prevents the possible production of germs and bacteria.

After the evacuation of the water through the toilet, we see that the system works, although it presents some points to bear in mind when it is installed in health centers. The sink and toilet should always be placed as close as possible to each other, otherwise the flow could stall, as the circulation through the pipes is by simple gravity. If you have long distances between them, the system won't work properly. Also, as mentioned, the water filtration system must be fast enough to prevent the return of the water into the pipe, with the possibility of the water flooding the basin. It is then proposed to research a type of filter, with similar or lower density but with the same filtering capability, like a dripping cloth used in kitchen drains, which allows grey water filtering, decanting the solid remains in the same way.

\section{CONCLUSIONS}

- The system which has been designed, built, tested and evaluated has been well received and has been adopted.

- It is determined that the methods and tools used have served to achieve a product that may have a real impact, starting from its use and production in series.

- It is found that there is a need in Tucumán for environmentally friendly systems that improve the quality of life of their users. The necessity for the following is noted: researching reports on the need for environmental sustainability, in general, and on the rational use of water, in particular; to the promotion of information refer to water saving and habitat sustainability.

\section{REFERENCES}

[1] Passarini, K., Gamarra, F., Vanalle, R. \& Santana, J., Reutilización de las aguas residuales en la irrigación de plantas y en la recuparación de los suelos. La Serena, Chile, 2012.

[2] Ingeniero, J. \& Moscoso C., Tratamiento y uso de aguas residuales domésticas cepis / ops / oms, 2001.

[3] Grupo de trabajo de la Comisión Sectorial de Aguas Grises. Guía Técnica Española de Recomendaciones para el Reciclaje de Aguas Grises en Edificios. Aqua España, Madrid, España [LM1] [U2], 2011. 